\title{
BMJ Open Concurrent use of opioids and benzodiazepines/Z-drugs in Alberta, Canada and the risk of hospitalisation and death: a case cross-over study
}

\author{
Vishal Sharma (D , , ${ }^{1}$ Scot H Simpson, ${ }^{2}$ Salim Samanani, ${ }^{3}$ Ed Jess, ${ }^{4}$ \\ Dean T Eurich (D)
}

To cite: Sharma V,

Simpson SH, Samanani S, et al. Concurrent use of opioids and benzodiazepines/Z-drugs in Alberta, Canada and the risk of hospitalisation and death: a case cross-over study. BMJ Open 2020;10:e038692. doi:10.1136/ bmjopen-2020-038692

- Prepublication history and supplemental materials or this paper is available online. To view these files, please visit the journal online (http://dx.doi. org/10.1136/bmjopen-2020038692).

Received 20 March 2020 Revised 05 October 2020 Accepted 26 0ctober 2020

Check for updates

(c) Author(s) (or their employer(s)) 2020. Re-use permitted under CC BY-NC. No commercial re-use. See rights and permissions. Published by BMJ.

${ }^{1}$ School of Public Health, University of Alberta, Edmonton, Alberta, Canada

${ }^{2}$ Faculty of Pharmacy and

Pharmaceutical Sciences,

University of Alberta, Edmonton, Alberta, Canada

${ }^{3}$ Okaki Health Intelligence,

Calgary, Alberta, Canada

${ }^{4}$ The College of Physicians \&

Surgeons of Alberta, Edmonton, Alberta, Canada

Correspondence to

Professor Dean T Eurich;

deurich@ualberta.ca

\section{ABSTRACT}

Objectives Coprescribing of benzodiazepines/Z-drugs (BZDs) and opioids is a drug-use pattern of considerable concern due to risk of adverse events. The objective of this study is to estimate the effect of concurrent use of BZDs on the risk of hospitalisations/emergency department (ED) visits and deaths among opioid users.

Design, setting and participants We conducted a population-based case cross-over study during 20162018 involving Albertans 18 years of age and over who received opioids. From this group, we identified 1056773 people who were hospitalised or visited the ED, and 31998 who died.

Intervention Concurrent use of opioids and BZDs.

Outcomes We estimated the risk of incident all-cause hospitalisation/ED visits and all-cause mortality associated with concurrent BZD use by applying a matched-pair analyses comparing concurrent use to opioid only use. Results Concurrent BZD use occurred in $17 \%$ of opioid users (179 805/1 056 773). Overall, concurrent use was associated with higher risk of hospitalisation/ED visit (OR $1.13, p<0.001)$ and all cause death (OR 1.90; $p<0.001)$. The estimated risk of hospitalisation/ED visit was highest in those $>65$ ( $0 R 1.5 ; p<0.001)$, using multiple health providers $(0 R 1.67 ; p<0.001)$ and $>365$ days of opioid use (OR 1.76; $p<0.001)$. Events due to opioid toxicity were also associated with concurrent use (OR 1.8; $p<0.001)$. Opioid dose-response effects among concurrent patients who died were also noted (OR $3.13 ; p<0.001)$.

Interpretation Concurrent use of opioids and BZDs further contributes to the risk of hospitalisation/ED visits and mortality in Alberta, Canada over opioid use alone, with higher opioid doses, older age and increased number of unique health providers carrying higher risks. Regulatory bodies and health providers should reinforce safe drug-use practices and be vigilant about coprescribing.

\section{INTRODUCTION}

In the context of the opioid crisis, concurrent use of opioids and benzodiazepines/Zdrugs (BZDs) represents a drug use pattern that is of substantial concern because of the increased risk of mortality. ${ }^{1-3}$ In Canada and the USA, the policy response to the opioid crisis has focused on establishing guidelines
Strengths and limitations of this study

- The use of a large population-based sample with near complete capture of all opioid and benzodiazepine dispensations from community pharmacies in Alberta.

- The case cross-over methodology is a good fit for studies in pharmacoepidemiology like ours since the effect of many confounders can be substantially controlled.

- We considered patient subgroups that have not previously been studied with respect to concurrent use of opioids and benzodiazepines.

- We assumed that patients took their medications as prescribed and recorded in the administrative data set.

- There is always residual confounding and importantly, unknown factors which may have changed between the control and case windows could have affected our results.

for safe and appropriate prescribing of opioids. ${ }^{14}$ Although there are no specific clinical guidelines on indications for concurrent use of opioids and BZDs, there are numerous evidence-based recommendations warning against concurrent prescribing of these medications ${ }^{145}$ and previous literature suggests that opioids and BZDs cannot be targeted by safe use policies in isolation. ${ }^{6}$ Despite these warnings, opioids and BZDs are still being coprescribed at alarming rates, as shown in our previous work using Alberta data. ${ }^{7}$ Data from the USA also show an increasing trend in coprescribing of opioids and BZDs ${ }^{2} 89$ and $50 \%$ of opioid-related deaths in Ontario and Manitoba, Canada involved BZDs. ${ }^{10} 11$ Furthermore, two large studies in the USA showed that concurrent use of opioids and BZDs carried a higher risk of hospital admission and mortality than opioid use alone. ${ }^{23}$ However, the Canadian studies did not quantify the risk associated with concurrent use and 
the two US studies used populations limited to US military veterans and those that were privately insured which may not be generalisable to the Canadian population.

To our knowledge, no Canadian population-based studies have quantified the effect of concurrent BZD and opioid use on outcomes such as hospitalisations and mortality using the characteristics that we and others have identified as relevant. ${ }^{23}$ A knowledge gap exists on the risks of coprescribing of these agents, especially when looking at opioid dose, duration of concurrent use and healthcare utilisation. Using a case cross-over study design, we aimed to examine the association between concurrent use of opioids and BZDs and adverse health outcomes and hypothesised that concurrent use would further increase risk of these outcomes. Our results will help fill the evidence gap on the adverse outcomes associated with concurrent prescribing of opioids and BZDs.

\section{METHODS}

\section{Data sources}

Demographic information and dispensation records from community pharmacies were obtained from Alberta Netcare Pharmaceutical Information Network (PIN). Information on hospitalisations and emergency department (ED) visits was collected using the Canadian Institute for Health Information's Discharge Abstract Database and National Ambulatory Care Reporting System. Physician visits/claims and death records were provided by Alberta Health and Population and Vital Statistics, respectively. Using anonymised patient-level identifiers, these databases were linked together to establish a complete description of drug exposures and health outcomes.

\section{Identification of patients and outcomes}

Two distinct analysis cohorts were generated corresponding to two different study periods. For the hospitalisation and ED analyses, all subjects in Alberta, Canada who received a dispensation for an opioid between 1 January 2016 and 31 December 2018, 18 years of age and over were included. For mortality analyses, all subjects who received a dispensation for an opioid between 1 January 2016 and 31 December 2017 were included. This distinction was required as mortality data was not yet available for 2018 as reporting is 12-24 months delayed in the province.

Our primary outcomes among the cohort of opioid users were all cause, incident hospitalisations or ED visits during 1 January 2016-31 December $2018 \quad(n=1056773)$ and all cause mortality during 1 January 2016-31 December 2017 $(n=31998)$. The secondary outcome was incident hospitalisation or ED visit due to ICD-10 (International Classification of Diseases, Tenth Revision) diagnoses related to opioid toxicity (ICD10 F04-F99, T400-T404, T406) between 1 January 2016 and 31 December 2018 as this endpoint maybe more specific to the population using BZD and opioids. ${ }^{12}$ The date of the event served as the index date for all analyses (see online supplemental efigure 1).

\section{Exposure}

The exposure of interest was whether an opioid patient also used a BZD concurrently during the two study periods. We considered 'use' as any day on which a patient had a supply of medication on hand on the basis of the date and days' supply of each dispensation as others have. ${ }^{2}$ As described in our previous work, ${ }^{7}$ for each patient, a day was categorised as concurrent if it was covered by both an opioid and BZD. For every patient in our two previously defined opioid cohorts and study periods, each day of follow-up was categorised into one of four mutually exclusive groups of exposures: (1) neither opioid nor BZD use (none), (2) opioid only use, (3) BZD only use and (4) any concurrent use of opioid and BZD (concurrent). In our case cross-over analyses, 'none', 'opioid only', 'BZD only' and 'concurrent' refer to drug use during the case crossover study windows. We identified opioid and BZD prescriptions using Anatomical Therapeutic Chemical codes $^{13}$ (see online supplemental etable 1) and included all Health Canada approved ${ }^{14}$ opioid and BZD formulations which are monitored in the Alberta Triplicate Prescription Program. ${ }^{15}$

\section{Design and statistical analyses}

An opioid user was defined as anyone who received at least one dispensation for an opioid and concurrent use was defined as at least 1 day of overlap between an opioid and BZD. Healthcare utilisation ${ }^{16}$ was defined by number of unique providers visited and number of opioid prescriptions dispensed. Opioid doses were standardised into oral morphine equivalents (OME) using conversion factors outlined by the Triplicate Prescription Program ${ }^{17}$ in Alberta, Canada.

We first conducted a descriptive analysis of our study population and performed pairwise comparisons between 'opioid only users' and 'concurrent users' using t-tests and $\chi^{2}$ tests of independence using data from 2016 to 2018 (see online supplemental efigure 1). Then, we used the case cross-over design to estimate if concurrent use increased the risk of our defined outcomes. In a case cross-over study, each person serves as their own control; consequently, eliminating confounding due to age, sex and other fixed patient factors. ${ }^{18}$ This methodology is increasingly being used to evaluate exposures encountered in pharmacoepidemiology and when using administrative databases. ${ }^{18-20}$

Conditional logistic regression was used to contrast the four defined exposure categories in the 7-day risk period immediately before the event with the 7-day control period 1 month earlier. We chose the 1-month time period based on other published pharmacoepidemiology studies using this methodology. ${ }^{21}$ For each of the defined exposure groups, we estimated the risk of incident hospitalisation/ED visits and mortality using ORs and their associated 95\% CIs. The opioid only exposure group was used as the reference group in order to estimate the risk of concurrent use relative to opioid only use. The analyses were stratified into the following subgroups using data within the year prior to the outcome (see online supplemental efigure 1): sex, age at admission or death, total 
Table 1 Characteristics and summary statistics of opioid users with incident hospitalisations/emergency department visits using data from 2016 to 2018

\begin{tabular}{|c|c|c|c|}
\hline Characteristic & $\begin{array}{l}\text { Total no }(\%) \text { of } \\
\text { patients }{ }^{*}=1056773 \dagger\end{array}$ & $\begin{array}{l}\text { No }(\%) \text { of concurrent } \\
\text { users* } n=179805 \ddagger\end{array}$ & $\begin{array}{l}\text { No }(\%) \text { of non-concurrent } \\
\text { opioid users* } n=876968 \S\end{array}$ \\
\hline Opioid users & $1056773(100)$ & $179805(100)$ & $876968(100)$ \\
\hline No of dispensations for opioids & $11240195(-)$ & $5855666(-)$ & $5384529(-)$ \\
\hline No of dispensations for BZDs & $6050709(-)$ & $4767945(-)$ & 1282764 (-)ף \\
\hline \multicolumn{4}{|l|}{ Sex } \\
\hline Female & 581457 (55) & $109128(60.7)$ & $472411(53.9)$ \\
\hline Male & $475316(45)$ & $70677(39.3)$ & $404557(46.1)$ \\
\hline Age at admission, year, median (IQR) & $49(34-62)$ & $56(43-67)$ & $47(32-61)$ \\
\hline Mean (SD) & $48.7(18.1)$ & $55.2(17.0)$ & $47.4(18.1)$ \\
\hline $10-20$ & $48721(4.6)$ & $2276(1.3)$ & $46445(5.3)$ \\
\hline $21-40$ & $339380(32.1)$ & $36192(20.1)$ & $303188(34.5)$ \\
\hline $41-65$ & $464720(44.0)$ & $90626(50.4)$ & $374094(42.7)$ \\
\hline$>65$ & $203909(19.3)$ & $50708(28.2)$ & $153201(17.5)$ \\
\hline $\begin{array}{l}\text { No of unique prescribers visited, median } \\
\text { (IQR) }\end{array}$ & $2(1-3)$ & $4(2-6)$ & $1(1-2)$ \\
\hline Mean (SD) & $2.3(2.2)$ & $4.5(3.4)$ & $1.9(1.4)$ \\
\hline 1 & $508745(48.1)$ & $19252(10.7)$ & $489493(55.8)$ \\
\hline 2 & $246935(23.4)$ & $33594(18.7)$ & $213341(24.3)$ \\
\hline 3 & $124773(11.8)$ & $33473(18.6)$ & $91300(10.4)$ \\
\hline 4 & $66825(6.3)$ & $26573(14.8)$ & $40252(4.6)$ \\
\hline$>5$ & $109495(10.4)$ & $66913(37.2)$ & $42582(4.9)$ \\
\hline $\begin{array}{l}\text { No of unique pharmacies visited, median } \\
\text { (IQR) }\end{array}$ & $2(1-3)$ & $3(2-5)$ & $2(1-2)$ \\
\hline Mean (SD) & 2.37 (2.18) & $4.1(3.8)$ & $2.02(1.45)$ \\
\hline 1 & $431651(40.8)$ & 29486 (16.4) & $402165(45.8)$ \\
\hline 2 & 301730 (28.5) & 41064 (22.8) & 260666 (29.7) \\
\hline 3 & $151297(14.3)$ & $33578(18.8)$ & $117710(13.4)$ \\
\hline 4 & $73698(7.0)$ & $23356(13.0)$ & $50342(5.7)$ \\
\hline$>5$ & $98406(9.3)$ & $52321(29.1)$ & $46085(5.3)$ \\
\hline $\begin{array}{l}\text { Total no of opioid prescriptions dispensed, } \\
\text { median (IQR) }\end{array}$ & $2(1-4)$ & $8(2-29)$ & $1(1-3)$ \\
\hline Mean (SD) & $9.8(51.4)$ & $32.6(101.5)$ & $5.2(30.9)$ \\
\hline $1-10$ & 919059 (87.0) & 100809 (56.0) & 818250 (93.3) \\
\hline $11-20$ & $48371(4.6)$ & $22796(12.7)$ & $25575(2.9)$ \\
\hline $20-30$ & $23706(2.2)$ & $13163(7.3)$ & $10543(1.2)$ \\
\hline$>31$ & $65637(6.2)$ & $43037(23.9)$ & $22600(2.6)$ \\
\hline $\begin{array}{l}\text { Total cumulative days of opioid use, median } \\
\text { (IQR) }\end{array}$ & $11(5-39)$ & $104(21-522)$ & $9(5-23)$ \\
\hline Mean (SD) & 94.5 (224) & $297.9(358.0)$ & $52.8(154.7)$ \\
\hline $1-30$ & 744607 (70.5) & $54670(30.4)$ & 689937 (78.7) \\
\hline $31-60$ & $94659(9.0)$ & 20406 (11.4) & $74253(8.5)$ \\
\hline $61-90$ & $35536(3.4)$ & $10934(6.1)$ & $24602(2.8)$ \\
\hline$>90$ & $181971(17.2)$ & 93795 (52.2) & $88176(10.1)$ \\
\hline \multicolumn{4}{|c|}{ No of people that received a dispensation for specified opioid molecule and daily $\mathrm{OME}^{\star *}$} \\
\hline Buprenorphine/naloxone & $7995(0.76)$ & 3005 (1.7) & $7451(0.85)$ \\
\hline
\end{tabular}

Continued 
Table 1 Continued

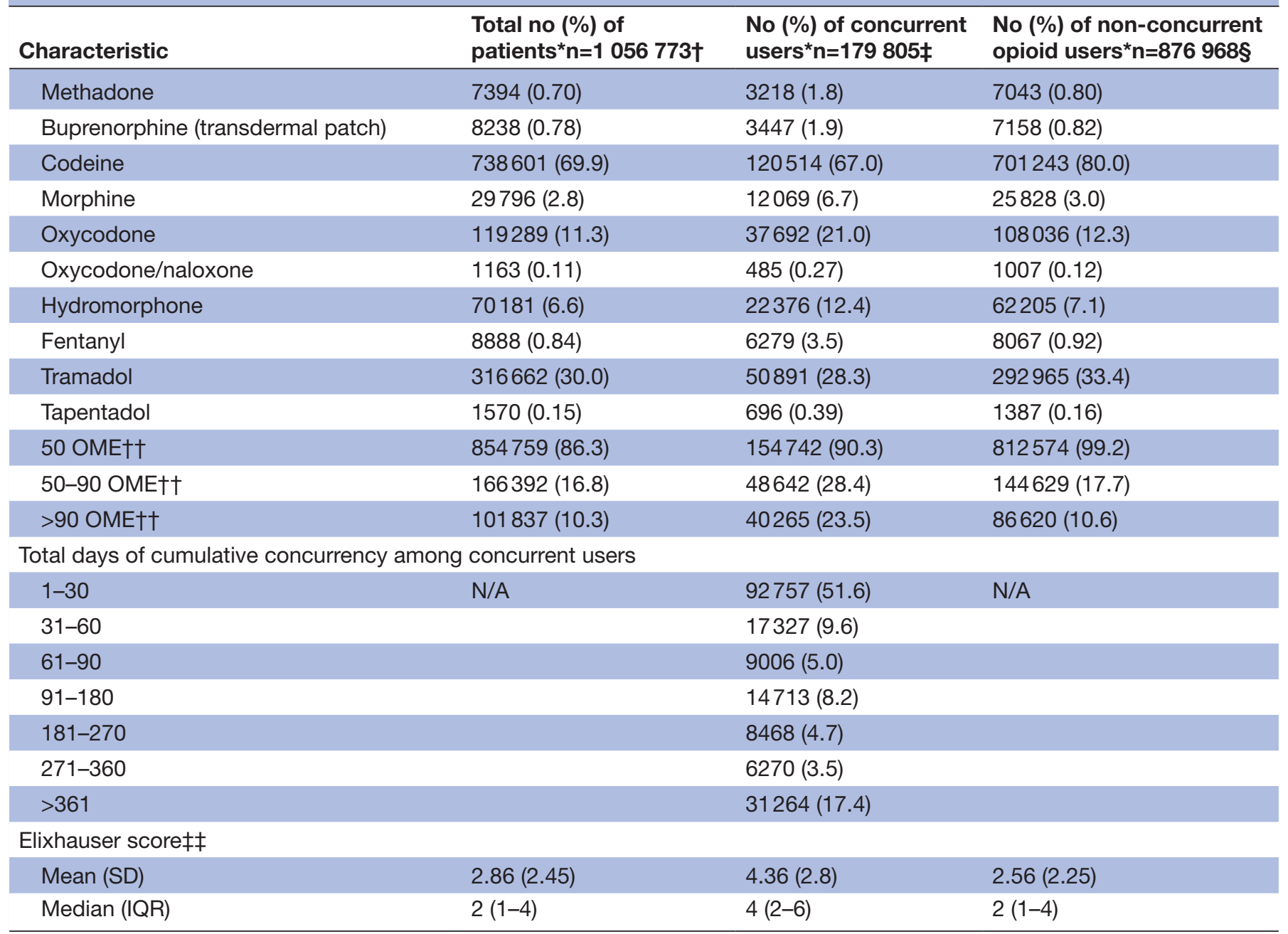

All pairwise comparisons between concurrent and opioid only users had $\mathrm{p}<0.001$.

*Unless otherwise indicated.

$\dagger \mathrm{n}=990098$ for OME analyses.

$\ddagger \mathrm{n}=171457$ for OME analyses.

$\S \mathrm{n}=818641$ for OME analyses.

IIf patients had BZD use outside of the study windows, then this was captured in our summary statistics.

${ }^{* \star}$ Defined as having at least 1 day at specified dose or molecule.

††OME=oral morphine equivalents, buprenorphine and methadone dropped from OME analysis.

‡¥Determined using data from 2012 to 2016.

BZD, benzodiazepines/Z-drug; N/A, not available; OME, oral morphine equivalent.

days of cumulative concurrency prior to event, total days of previous opioid use, healthcare utilisation, OME. All analyses were performed using STATA/MP V.15.1 (StataCorp)

\section{Sensitivity analyses}

We performed the primary analyses on a subset of the population that excluded cancer and palliative patients like others have ${ }^{322}$ by removing all patients that had relevant ICD codes (ICD9: 140-239, V66.7; ICD10: C00-D49, Z51) at any time between 2012-2018 identified from the abovementioned databases. We also performed the analyses after adjusting the length of both the risk and control periods to 3 and 10 days and adding a second control period that preceded the event by 2 weeks.

\section{Patient and public involvement}

This research was done without patient involvement. Patients were not invited to comment on the study design and were not consulted to develop patient-relevant outcomes or interpret the results. Patients were not invited to contribute to the writing or editing of this document for readability or accuracy. There are no plans to disseminate the results of the research to study participants.

\section{RESULTS}

There were 1056773 patients in Alberta classified as opioid users who were hospitalised or visited the ED during 2016-2018 (table 1). Among this cohort, 17\% 
Table 2 Risk of all cause hospitalisation or emergency department visits in people using opioids and benzodiazepine receptor modulators during 2016-2018

\begin{tabular}{|c|c|c|c|c|c|c|c|}
\hline \multirow[b]{3}{*}{ Patient group } & \multicolumn{7}{|c|}{ Analysis group based on exposure category* } \\
\hline & \multicolumn{2}{|l|}{ None } & \multirow{2}{*}{$\begin{array}{l}\begin{array}{l}\text { Opioid only } \\
\text { (reference) }\end{array} \\
\text { OR } \\
\end{array}$} & \multicolumn{2}{|c|}{ Benzodiazepine† only } & \multicolumn{2}{|l|}{ Concurrent } \\
\hline & OR (P value) & $95 \% \mathrm{Cl}$ & & OR (P value) & $95 \% \mathrm{Cl}$ & OR ( $P$ value) & $95 \% \mathrm{Cl}$ \\
\hline Overall population & $0.21(<0.001)$ & 0.20 to 0.21 & 1 & $0.46(<0.001)$ & 0.45 to 0.48 & $1.13(<0.001)$ & 1.10 to 1.17 \\
\hline \multicolumn{8}{|l|}{ Sex } \\
\hline Female & $0.24(<0.001)$ & 0.23 to 0.25 & 1 & $0.51(<0.001)$ & 0.49 to 0.52 & $1.19(<0.001)$ & 1.14 to 1.23 \\
\hline Male & $0.18(<0.001)$ & 0.18 to 0.19 & 1 & $0.43(<0.001)$ & 0.41 to 0.45 & $1.10(<0.001)$ & 1.05 to 1.16 \\
\hline \multicolumn{8}{|l|}{ Age at admission } \\
\hline $20-40$ & $0.16(<0.001)$ & 0.15 to 0.16 & 1 & $0.33(<0.001)$ & 0.31 to 0.35 & $0.96(0.33)$ & 0.88 to 1.04 \\
\hline $40-65$ & $0.23(<0.001)$ & 0.22 to 0.23 & 1 & $0.48(<0.001)$ & 0.46 to 0.50 & $1.12(<0.001)$ & 1.07 to 1.18 \\
\hline$>65$ & $0.30(<0.001)$ & 0.29 to 0.31 & 1 & $0.73(<0.001)$ & 0.69 to 0.77 & $1.50(<0.001)$ & 1.39 to 1.61 \\
\hline \multicolumn{8}{|c|}{ Total days of cumulative concurrency } \\
\hline $1-30$ & $0.33(<0.001)$ & 0.31 to 0.35 & 1 & $0.72(<0.001)$ & 0.67 to 0.78 & $2.47(<0.001)$ & 2.26 to 2.70 \\
\hline $31-90$ & $0.45(<0.001)$ & 0.41 to 0.49 & 1 & $1.05(0.36)$ & 0.95 to 1.17 & $1.50(<0.001)$ & 1.34 to 1.67 \\
\hline $91-180$ & $0.44(<0.001)$ & 0.39 to 0.49 & 1 & $1.09(0.24)$ & 0.95 to 1.24 & $1.45(<0.001)$ & 1.28 to 1.64 \\
\hline $181-365$ & $0.42(<0.001)$ & 0.37 to 0.48 & 1 & $1.11(<0.11)$ & 0.97 to 1.3 & $1.57(<0.001)$ & 1.40 to 1.76 \\
\hline$>365$ & $0.26(<0.001)$ & 0.23 to 0.29 & 1 & $1.26(<0.001)$ & 1.11 to 1.41 & $1.82(<0.001)$ & 1.67 to 1.99 \\
\hline$>900$ & $0.13(<0.001)$ & 0.09 to 0.21 & 1 & $1.64(0.01)$ & 1.12 to 2.38 & $3.15(<0.001)$ & 2.41 to 4.11 \\
\hline \multicolumn{8}{|c|}{ Total days of opioid use } \\
\hline $1-7$ & $0.04(<0.001)$ & 0.03 to 0.05 & 1 & $0.08(<0.001)$ & 0.07 to 0.09 & $0.90(0.40)$ & 0.72 to 1.14 \\
\hline $8-30$ & $0.15(<0.001)$ & 0.14 to 0.16 & 1 & $0.30(<0.001)$ & 0.28 to 0.32 & $1.21(0.002)$ & 1.07 to 1.38 \\
\hline $31-90$ & $0.34(<0.001)$ & 0.33 to 0.35 & 1 & $0.71(<0.001)$ & 0.66 to 0.76 & $1.36(<0.001)$ & 1.22 to 1.51 \\
\hline $91-180$ & $0.48(<0.001)$ & 0.46 to 0.51 & 1 & $1.05(0.35)$ & 0.95 to 1.15 & $1.54(<0.001)$ & 1.37 to 1.73 \\
\hline $181-365$ & $0.54(<0.001)$ & 0.52 to 0.57 & 1 & $1.27(<0.001)$ & 1.15 to 1.40 & $1.73(<0.001)$ & 1.56 to 1.92 \\
\hline$>365$ & $0.41(<0.001)$ & 0.39 to 0.42 & 1 & $1.21(<0.001)$ & 1.12 to 1.32 & $1.76(<0.001)$ & 1.66 to 1.86 \\
\hline \multicolumn{8}{|c|}{ No of opioid dispensations } \\
\hline $1-10$ & $0.16(<0.001)$ & 0.16 to 0.17 & 1 & $0.34(<0.001)$ & 0.33 to 0.35 & $0.93(0.01)$ & 0.87 to 0.98 \\
\hline $9-30$ & $0.49(<0.001)$ & 0.47 to 0.51 & 1 & $1.20(<0.001)$ & 1.11 to 1.30 & $1.62(<0.001)$ & 1.50 to 1.74 \\
\hline$>30$ & $0.35(<0.001)$ & 0.33 to 0.37 & 1 & $1.09(0.10)$ & 0.98 to 1.21 & $1.77(<0.001)$ & 1.65 to 1.89 \\
\hline \multicolumn{8}{|c|}{ No of unique prescribers } \\
\hline 1 & $0.14(<0.001)$ & 0.13 to 0.14 & 1 & $0.30(<0.001)$ & 0.28 to 0.32 & $0.73(<0.001)$ & 0.65 to 0.81 \\
\hline 2 & $0.20(<0.001)$ & 0.19 to 0.20 & 1 & $0.41(<0.001)$ & 0.39 to 0.43 & $1.02(0.64)$ & 0.94 to 1.11 \\
\hline 3 & $0.26(<0.001)$ & 0.25 to 0.27 & 1 & $0.51(<0.001)$ & 0.48 to 0.54 & $1.30(<0.001)$ & 1.19 to 1.42 \\
\hline 4 & $0.32(<0.001)$ & 0.31 to 0.34 & 1 & $0.68(<0.001)$ & 0.63 to 0.73 & $1.54(<0.001)$ & 1.39 to 1.70 \\
\hline$>5$ & $0.38(<0.001)$ & 0.37 to 0.40 & 1 & $0.91(<0.001)$ & 0.86 to 0.96 & $1.67(<0.001)$ & 1.57 to 1.77 \\
\hline \multicolumn{8}{|c|}{ No of unique pharmacies } \\
\hline 1 & $0.14(<0.001)$ & 0.13 to 0.15 & 1 & $0.32(<0.001)$ & 0.31 to 0.35 & $0.95(0.25)$ & 0.86 to 1.04 \\
\hline 2 & $0.20(<0.001)$ & 0.19 to 0.21 & 1 & $0.45(<0.001)$ & 0.43 to 0.48 & $1.12(0.007)$ & 1.03 to 1.21 \\
\hline 3 & $0.27(<0.001)$ & 0.26 to 0.28 & 1 & $0.56(<0.001)$ & 0.52 to 0.59 & $1.24(<0.001)$ & 1.14 to 1.35 \\
\hline 4 & $0.31(<0.001)$ & 0.29 to 0.33 & 1 & $0.66(<0.001)$ & 0.61 to 0.71 & $1.47(<0.001)$ & 1.33 to 1.64 \\
\hline$>5$ & $0.39(<0.001)$ & 0.38 to 0.41 & 1 & $0.78(<0.001)$ & 0.73 to 0.83 & $1.47(<0.001)$ & 1.38 to 1.57 \\
\hline
\end{tabular}

${ }^{*}$ Risk interval=7 days before hospitalisation/emergency visit; control interval=7-day period 1 month before hospitalisation/emergency department visit.

†Includes all benzodiazepine receptor modulators. 


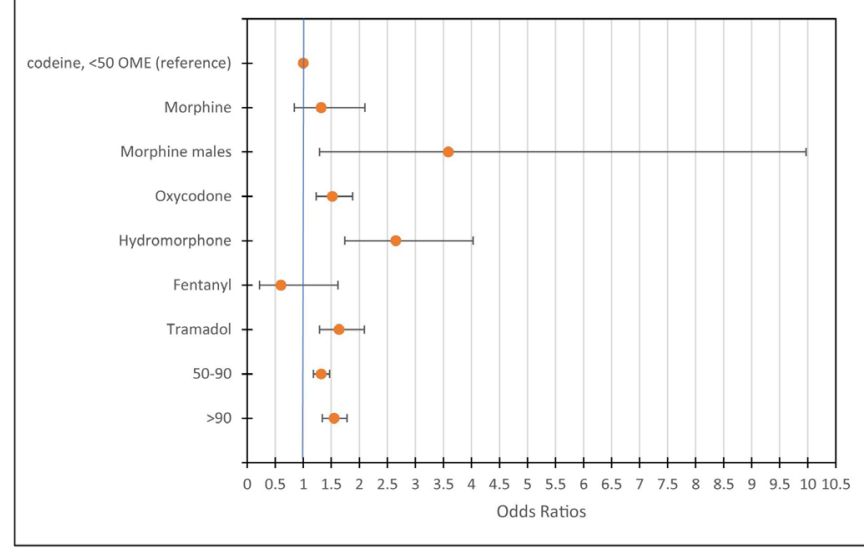

Figure 1 Risk of all cause hospitalisation or emergency department visits among concurrent users of opioids and benzodiazepines by molecule and opioid dose using codeine and $<50$ OME as reference groups. Bars represent $95 \% \mathrm{Cls}$. Dose is OME and $<50$ OME is the reference. Buprenorphine and methadone have been excluded. OME, oral morphine equivalent.

( $\mathrm{n}=179805)$ had at least 1 day of concurrent use with a BZD during follow-up. Similarly, there were 31998 patients in the death cohort and $34.5 \%(\mathrm{n}=11055)$ had at least 1 day of concurrent use.

\section{Hospitalisations or ED visits}

Compared with opioid only use, concurrent use of opioids and BZDs was associated with an elevated risk of hospitalisation or ED visit ((prevalence of exposure to concurrent use in control and case windows, respectively:2.1\% vs $3.3 \%$ ); OR 1.13; $\mathrm{p}<0.001$; table 2). After stratification, those over 65 years of age $(3.6 \%$ vs $4.8 \%$; OR 1.5 ; $p<0.001)$

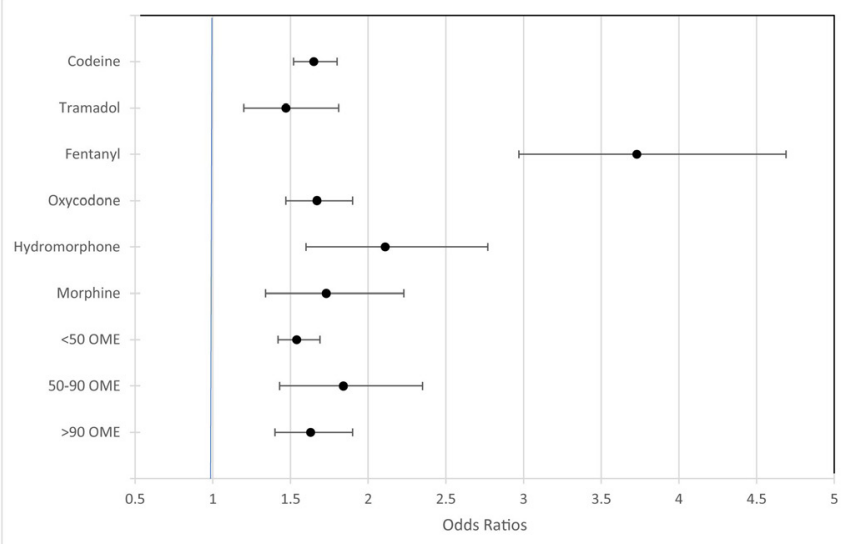

Figure 2 Risk of hospitalisation or emergency department visit comparing specific opioid molecules and opioid doses* used concurrently with BZDs† to their respective monotherapy counterpartsł. Bars represent 95\% Cls. *Opioid dose is OME; buprenorphine and methadone have been excluded. †Benzodiazepine receptor modulator (includes Zdrugs). $\ddagger$ For example, the ORs plotted for codeine represents the risk of codeine + BZD compared with codeine alone and that of $\angle 50$ OME represents the risk of $<50 \mathrm{OME}+\mathrm{BZD}$ compared with $<50$ OME alone. BZD, benzodiazepines/Zdrug; OME, oral morphine equivalent. and those visiting $>5$ health providers $(13.0 \%$ vs $16.5 \%$; OR 1.67; $\mathrm{p}<0.001$ ) had the highest risk associated with concurrent use. With respect to total days of concurrency prior to the event, although any duration of concurrency was associated with an increase in risk, one of the highest risks was observed in those that had concurrent use of less than a month (1-30 days) (1.4\% vs $5.8 \%$; OR 2.47 ; $\mathrm{p}<0.001$; table 2). Not unexpectant, increasing duration of previous use of opioids was also associated with an increasing estimated risk (table 2).

Among the concurrent patients who were hospitalised or visited an ED, morphine, oxycodone, hydromorphone and tramadol carried the highest risks when compared with codeine and used concurrently with BZDs (figure 1). As expected, there was an opioid dose response effect on estimated risk where higher OME's had higher risk compared with $<50 \mathrm{OME}$ among concurrent patients (figure 1). When specific opioid molecules and OME dose ranges were examined, an increased risk of hospitalisation or ED visit was noted for all opioid molecules and doses when used concurrently with a BZD (figure 2).

In the secondary analysis, the estimated risk of hospitalisation or ED visit was also higher in concurrent patients when compared with opioid only patients for admissions related to opioid toxicity (OR 1.8; $\mathrm{p}<0.001)$.

\section{Mortality}

We identified 31998 deaths between 2016 and 2017 in our cohort of opioid users. Estimated risk of death was substantially higher with concurrent use when compared with opioid only use when comparing the control and case windows $(12.7 \%$ vs $18.6 \%$; OR $1.90 ; \mathrm{p}<0.001)$ with males having a higher risk than females (table 3). Among concurrent patients, there was an opioid dose response effect on estimated risk of death with $>90$ OME associated with up to triple the risk when compared with $<50$ OME group (table 4). Similar to the trends in hospitalisations or ED visits, there was an elevated estimated risk of death ( $12.1 \%$ vs $49.1 \%$; OR 4.93 ; $\mathrm{p}<0.001)$ during the first 30 days of cumulative concurrent use (table 3 )

In sensitivity analyses, concurrent use was still associated with a higher risk of hospitalisation or ED visits and mortality when compared with opioid only use after adjusting the length of study windows, number of control windows, and when cancer and palliative patients were excluded.

\section{DISCUSSION}

Many clinical resources warn that BZDs should not be combined with opioids, ${ }^{145}$ yet our study showed a substantial proportion of patients using an opioid did so in combination with a BZD in Alberta, Canada. A concerning trend in adverse outcomes was observed with a near twofold increased risk of mortality associated with concurrent BZD and opioid use compared with opioid only use. In particular, those age $>65$ years, those visiting multiple health providers, and higher OME's were at 
Table 3 Risk of all cause death in 2016-2017 among opioid users and subgroups of patients, ( $n=31998)$

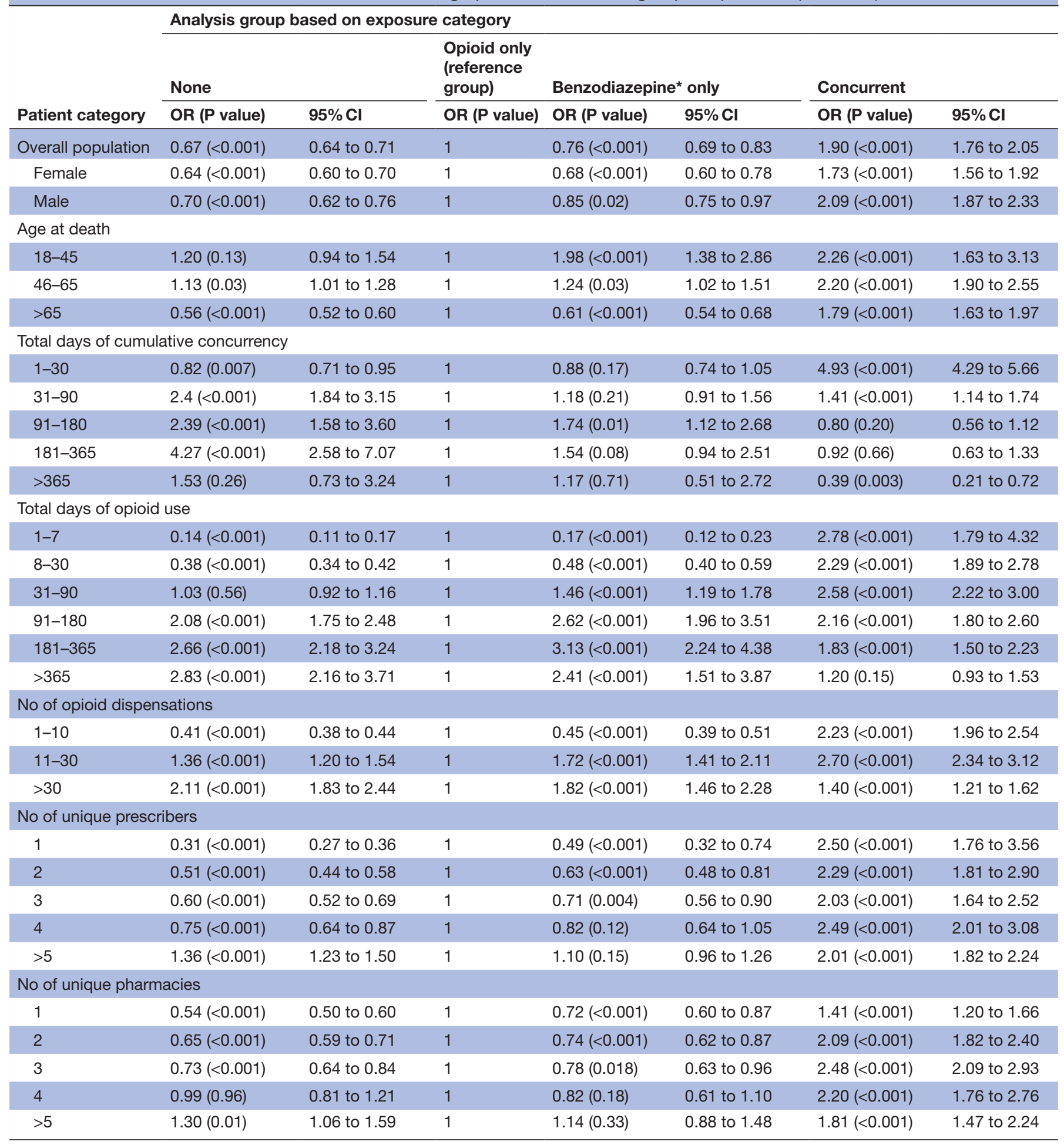

*Benzodiazepine receptor modulator (includes Z-drugs).

control interval, seven-day period one month before death; risk interval, seven days before death.

highest relative risks. Importantly, the data also show that one of the highest risks was observed in those that had concurrent use of less than a month with a near 2.5-fold relative increase in hospitalisations or ED visits. Although perceived to be safer, tramadol concurrently used with
BZDs had a substantially higher risk than codeine, especially among females.

Our findings are consistent with two large studies done in the USA. Sun $e t a l^{2}$ reported that $17 \%$ of opioid patients concurrently used a BZD and that higher durations of 
Table 4 Risk of all cause death in 2016-2017 among patients coprescribed BZDs and opioids stratified by OME $(\mathrm{n}=31998)$

\begin{tabular}{|c|c|c|c|}
\hline \multirow[b]{3}{*}{ Category } & \multicolumn{3}{|l|}{ OME } \\
\hline & $\begin{array}{l}<50 \\
\text { (reference } \\
\text { group) }\end{array}$ & $50-90$ & $>90$ \\
\hline & $\begin{array}{l}\text { OR ( } \mathrm{P} \text { value) } \\
95 \% \mathrm{Cl}\end{array}$ & $\begin{array}{l}\text { OR ( } \mathrm{P} \text { value) } \\
95 \% \mathrm{Cl}\end{array}$ & $\begin{array}{l}\text { OR ( } \mathrm{P} \text { value) } \\
95 \% \mathrm{Cl}\end{array}$ \\
\hline Overall population & 1 & $\begin{array}{l}1.72(<0.001) \\
1.35 \text { to } 2.19\end{array}$ & $\begin{array}{l}3.13(<0.001) \\
2.50 \text { to } 3.92\end{array}$ \\
\hline Female & 1 & $\begin{array}{l}1.76(<0.001) \\
1.25 \text { to } 2.48\end{array}$ & $\begin{array}{l}3.22(<0.001) \\
2.35 \text { to } 4.40\end{array}$ \\
\hline Male & 1 & $\begin{array}{l}1.68(0.003) \\
1.19 \text { to } 2.37\end{array}$ & $\begin{array}{l}3.04(<0.001) \\
2.20 \text { to } 4.19\end{array}$ \\
\hline \multicolumn{4}{|l|}{ Age at death } \\
\hline $18-45$ & 1 & $\begin{array}{l}0.90(0.83) \\
0.35 \text { to } 2.31\end{array}$ & $\begin{array}{l}2.31(0.08) \\
0.92 \text { to } 5.85\end{array}$ \\
\hline $46-65$ & 1 & $\begin{array}{l}2.19(<0.001) \\
1.41 \text { to } 3.39\end{array}$ & $\begin{array}{l}2.78(<0.001) \\
1.84 \text { to } 4.18\end{array}$ \\
\hline$>65$ & 1 & $\begin{array}{l}1.60(0.003) \\
1.18 \text { to } 2.18\end{array}$ & $\begin{array}{l}3.41(<0.001) \\
2.57 \text { to } 4.52\end{array}$ \\
\hline
\end{tabular}

Buprenorphine and methadone were excluded.

BZD, benzodiazepines/Z-drugs; OME, oral morphine equivalent.

opioid use also carried higher risks of hospitalisation or ED visit with respect to concurrent users, findings that we also shared. However, compared with Sun et al our overall cohort risk was lower (OR 2.14 vs 1.13). This could be due to differences in study population and methodology; the Sun study included privately insured patients and used a retrospective analysis whereas we included all Albertans regardless of coverage and used a case-crossover design. The other study, done by Park et al, estimated risk of death among US veterans exposed to concurrent use of opioids and BZDs. ${ }^{3}$ Although both of our studies associated concurrent use of opioids and BZDs with increased risk of death, overall and in an opioid dose-dependent manner, the Park et al risk estimates were much higher than ours, almost double. Of note, however, Park et al included only veterans, which proportionally represented an older population than ours. When our death analysis was stratified by age, our risk of death estimates were very similar to the Park et al study. Furthermore, compared with the general population, veterans in the USA have a higher prevalence of substance use disorders and mental illness, which carry their own risks. ${ }^{23-25}$ As other studies have observed, the estimated risk of an opioid-related death from taking 50-90 OME was double when compared with lower OME doses. ${ }^{22}$ Estimates from our analyses indicate that this risk could increase by a factor of $2-3 \mathrm{x}$ from the addition of a BZD, depending on the age of the patient. Indeed, our findings showed that adding a BZD to any opioid molecule and to any opioid dose multiplied the risk of hospitalisation or ED visit or death.

Our finding that hospitalisation or ED visit and mortality risks were higher during the initial periods of concurrent use are also similar to another study done in the USA. ${ }^{26}$ Both of our estimates associate a higher risk during the first few days of concurrent use as more susceptible patients may experience adverse outcomes earlier in concurrent use, thus signalling that even short periods of concurrent use carry risks.

The strengths of our study include the large populationbased sample with near complete capture of all opioid and BZD dispensations from community pharmacies using PIN. As well, hospitalisations and ED visits, and mortality from Alberta Health and Vital Statistics were also used to identify our outcomes. Since we used a case cross-over design, many confounding variables would have been completely controlled for in our analysis (eg, age, sex, comorbidities) relative to that of other studies conducted to date, however, there could be residual confounding and bias due to the fact that opioid only users could be different than concurrent users in characteristics which our data may not adequately capture. Importantly, other unknown factors which may have changed between the control and case windows could have affected our results. Another limitation is that we are assuming that patients took their medications as prescribed. Medication adherence in opioid users is a challenging issue. ${ }^{27}$

Despite the messages from safe opioid prescribing guidelines, ${ }^{14}$ our findings show that Alberta, Canada still experiences troubling trends and risks associated with concurrent use of opioids and BZDs. Although total prescribed OME's have declined across Canada during the past few years, ${ }^{28}$ the trend with concurrent use of opioids and BZDs is unknown and may in fact be increasing. ${ }^{2}{ }^{8}$ From a clinical perspective, prescribers should closely follow opioid use guidelines and avoid concurrent prescribing with BZDs in most clinical scenarios. ${ }^{14}$ There is an opportunity for providers to monitor and potentially avoid concurrent use altogether or reassess for dose tapering. Future research should focus on why health providers and patients continue to accept and rely on concurrent prescribing of these agents as a form of treatment. Policy-makers and professional regulatory bodies should reinforce safe opioid use prescribing guidelines and educate providers about the additional risks associated with concurrent use of opioids and BZDs.

Acknowledgements This study is based on data provided by The Alberta Strategy for Patient Orientated Research (ABSPOR) SUPPORT unit and Alberta Health. The interpretation and conclusions contained herein are those of the researchers and do not necessarily represent the views of the Government of Alberta, ABSPOR or the College of Physicians \& Surgeons of Alberta (CPSA). Neither the Government of Alberta, ABSPOR, Alberta Health nor the CPSA expresses any opinion in relation to this study. This work was supported by Mitacs through the Mitacs Accelerate Program and the College of Physicians \& Surgeons of Alberta.

Contributors VS, DTE, SHS, SS and EJ were involved in the conception and design of the study. VS, SHS and DTE analysed the data. VS and DTE drafted the article. EJ, SHS and SS revised the article. All authors gave final approval of the version to be published. The corresponding author attests that all listed authors meet authorship criteria and that no others meeting the criteria have been omitted. DTE is the guarantor.

Funding The authors have not declared a specific grant for this research from any funding agency in the public, commercial or not-for-profit sectors. 
Competing interests All authors have completed the ICMJE uniform disclosure form at www.icmje.org/coi_disclosure.pdf and declare: no support from any organisation for the submitted work; SS has received research grants from the College of Physicians and Surgeons of Alberta; no other relationships or activities that could appear to have influenced the submitted work.

Patient consent for publication Not required.

Ethics approval This study was approved by the health ethics research board at the University of Alberta (\#Pro00083807).

Provenance and peer review Not commissioned; externally peer reviewed.

Data availability statement Data may be obtained from a third party and are not publicly available. No data are available.The data used in this study are not available for external analysis. However, administrative health data can be accessed from Alberta Health by following defined research protocols and confidentiality agreements.

Supplemental material This content has been supplied by the author(s). It has not been vetted by BMJ Publishing Group Limited (BMJ) and may not have been peer-reviewed. Any opinions or recommendations discussed are solely those of the author(s) and are not endorsed by BMJ. BMJ disclaims all liability and responsibility arising from any reliance placed on the content. Where the content includes any translated material, BMJ does not warrant the accuracy and reliability of the translations (including but not limited to local regulations, clinical guidelines, terminology, drug names and drug dosages), and is not responsible for any error and/or omissions arising from translation and adaptation or otherwise.

Open access This is an open access article distributed in accordance with the Creative Commons Attribution Non Commercial (CC BY-NC 4.0) license, which permits others to distribute, remix, adapt, build upon this work non-commercially, and license their derivative works on different terms, provided the original work is properly cited, appropriate credit is given, any changes made indicated, and the use is non-commercial. See: http://creativecommons.org/licenses/by-nc/4.0/.

ORCID iDs

Vishal Sharma http://orcid.org/0000-0001-7907-1183

Dean T Eurich http://orcid.org/0000-0003-2197-0463

\section{REFERENCES}

1 Dowell D. CDC guideline for prescribing opioids for chronic pain, 2016.

2 Sun EC, Dixit A, Humphreys K, et al. Association between concurrent use of prescription opioids and benzodiazepines and overdose: retrospective analysis. BMJ 2017;356:j760.

3 Park TW, Saitz R, Ganoczy D, et al. Benzodiazepine prescribing patterns and deaths from drug overdose among US veterans receiving opioid analgesics: case-cohort study. BMJ 2015;350:h2698.

4 Busse JW, Craigie S, Juurlink DN, et al. Guideline for opioid therapy and chronic noncancer pain. CMAJ 2017;189:E659-66.

5 ISMP Canada. Essential clinical skills for opioid prescribers, 2017. Available: https://www.ismp-canada.org/download/ OpioidStewardship/Opioid-Prescribing-Skills.pdf [Accessed Nov 2018].

6 Jones JD, Mogali S, Comer SD. Polydrug abuse: a review of opioid and benzodiazepine combination use. Drug Alcohol Depend 2012;125:8-18.
7 Sharma V, Weir D, Samanani S, et al. Characterisation of concurrent use of prescription opioids and benzodiazepine/Z-drugs in Alberta, Canada: a population-based study. BMJ Open 2019;9:e030858.

8 Hwang CS, Kang EM, Kornegay CJ, et al. Trends in the concomitant prescribing of opioids and benzodiazepines, 2002-2014. Am J Prev Med 2016;51:151-60.

9 Vozoris NT. Benzodiazepine and opioid co-usage in the US population, 1999-2014: an exploratory analysis. Sleep 2019;42

10 Gomes T. Latest trends in opioid-related deaths in Ontario: 1991 to 2015. Ontario Drug Policy Research Network, 2017.

11 Manitoba Health. Surveillance of opioid misuse and overdose in Manitoba [online], 2017. Available: https://www.gov.mb.ca/health/ publichealth/surveillance/docs/opioid/2017/q1_opioid.pdf

12 Gomes T, Khuu W, Martins D, et al. Contributions of prescribed and non-prescribed opioids to opioid related deaths: population based cohort study in Ontario, Canada. BMJ 2018;362:k3207.

13 World Health Organization. International language for drug utilization research, ATC/DDD, 2020. Available: https://www.whocc.no/ [Accessed Jun 2020].

14 Government of Canada. Drug product database online query, 2020. Available: https://health-products.canada.ca/dpd-bdpp/index-eng. jsp [Accessed June 2020].

15 College of Physicians and Surgeons of Alberta. TPP Alberta medications list. Triplicate prescription program, 2020. Available: http://www.cpsa.ca/tpp/tpp-medication-list/ [Accessed Jun 2020].

16 Lorig KR, Ritter P, Stewart AL, et al. Chronic disease selfmanagement program: 2-year health status and health care utilization outcomes. Med Care 2001;39:1217-23.

17 College of Physicians and Surgeons of Alberta. Tpp Alberta - OME and DDD conversion factors, 2020. Available: http://www.cpsa.ca/ tpp/ [Accessed Jun 2020].

18 Maclure M, Mittleman MA, aMA M. Should we use a case-crossover design? Annu Rev Public Health 2000;21:193-221.

19 Hallas J, Pottegård A. Use of self-controlled designs in pharmacoepidemiology. J Intern Med 2014;275:581-9.

20 Schneeweiss S, Sturmer T, Maclure M. Case crossover and casetime-control design. Pharmacoepi \& drug safety 1997, 1997.

21 Wright AJ, Gomes T, Mamdani MM, et al. The risk of hypotension following co-prescription of macrolide antibiotics and calciumchannel blockers. CMAJ 2011;183:303-7.

22 Gomes T, Mamdani MM, Dhalla IA, et al. And drug-related mortality in patients with nonmalignant PainOpioid dose and drug-related mortality. JAMA Internal Medicine 2011;171:686-91.

23 Vazan P, Golub A, Bennett AS. Substance use and other mental health disorders among Veterans returning to the inner city: prevalence, correlates, and rates of unmet treatment need. Subst Use Misuse 2013;48:880-93.

24 Lan C-W, Fiellin DA, Barry DT, et al. The epidemiology of substance use disorders in US veterans: a systematic review and analysis of assessment methods. Am J Addict 2016;25:7-24.

25 Wagner TH, Harris KM, Federman B, et al. Prevalence of substance use disorders among veterans and comparable nonveterans from the National survey on drug use and health. Psychol Serv 2007;4:149-57.

26 Hernandez I, He M, Brooks MM, et al. Exposure-Response association between concurrent opioid and benzodiazepine use and risk of opioid-related overdose in Medicare Part $D$ beneficiaries. JAMA Netw Open 2018;1:e180919.

27 Graziottin A, Gardner-Nix J, Stumpf M, et al. Opioids: how to improve compliance and adherence. Pain Pract 2011;11:574-81.

28 Abdesselam K, Dann MJ, Alwis R, et al. At-a-glance - Opioid surveillance: monitoring and responding to the evolving crisis. Health Promot Chronic Dis Prev Can 2018;38:312-6. 